\title{
2012
}

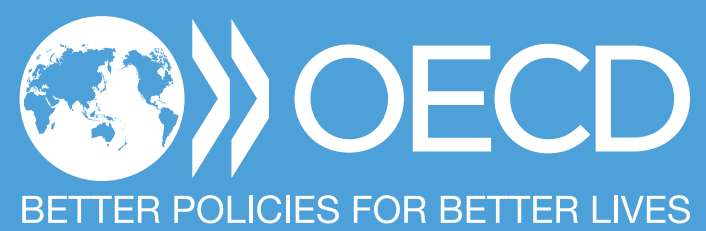

\section{RECOMMENDATION OF THE COUNCIL ON REGULATORY POLICY AND GOVERNANCE}




\section{Recommendation of the Council on Regulatory Policy and Governance}


This document and any map included herein are without prejudice to the status of or sovereignty over any territory, to the delimitation of international frontiers and boundaries and to the name of any territory, city or area.

Please cite this publication as:

OECD (2012), Recommendation of the Council on Regulatory Policy and Governance, OECD Publishing, Paris.

http://dx.doi.org/10.1787/9789264209022-en

ISBN 978-92-64-20902-2 (PDF)

Corrigenda to OECD publications may be found on line at: www.oecd.org/about/publishing/corrigenda.htm.

(C) OECD 2012

You can copy, download or print OECD content for your own use, and you can include excerpts from OECD publications, databases and multimedia products in your own documents, presentations, blogs, websites and teaching materials, provided that suitable acknowledgment of the source and copyright owner is given. All requests for public or commercial use and translation rights should be submitted to rights@oecd.org. Requests for permission to photocopy portions of this material for public or commercial use shall be addressed directly to the Copyright Clearance Center (CCC) at info@copyright.com or the Centre français d'exploitation du droit de copie (CFC) at contact@cfcopies.com. 


\section{The OECD Regulatory Policy Committee}

The mandate of the Regulatory Policy Committee is to assist members and non-members in building and strengthening capacity for regulatory quality and regulatory reform. The Regulatory Policy Committee is supported by staff within the Regulatory Policy Division of the Public Governance and Territorial Development Directorate.

The OECD Public Governance and Territorial Development Directorate's unique emphasis on institutional design and policy implementation supports mutual learning and diffusion of best practice in different societal and market conditions. The goal is to help countries build better government systems and implement policies at both national and regional level that lead to sustainable economic and social development.

For more information, please contact Nick Malyshev (nick.malyshev@oecd.org) or Céline Kauffmann (celine.kauffmann@oecd.org), or visit our website: www.oecd.org/gov/regulatory-policy/.

\section{The OECD GOV Mission Statement}

Our mission is to help governments at all levels design and implement strategic, evidence-based and innovative policies to strengthen public governance, respond effectively to diverse and disruptive economic, social and environmental challenges and deliver on government's commitments to citizens. 


\section{FOREWORD BY THE OECD SECRETARY-GENERAL}

The global financial and economic crisis has uncovered major failings in governance and regulation, which have undermined trust in public and private institutions alike. Amid ongoing economic uncertainty, establishing a well-functioning national regulatory framework for transparent and efficient markets is central to re-injecting confidence and restoring growth.

This Recommendation of the Council of the OECD on Regulatory Policy and Governance is the first comprehensive international statement on regulatory policy since the crisis. The Recommendation:

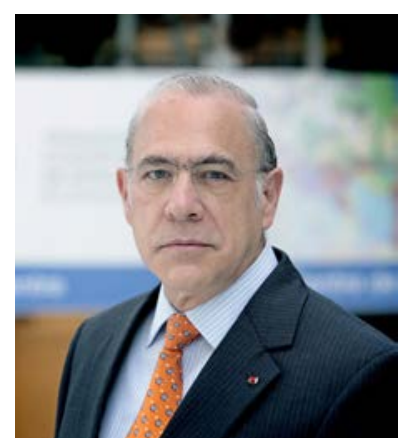

» provides governments with clear and timely guidance on the principles, mechanisms and institutions required to improve the design, enforcement and review of their regulatory framework to the highest standards;

» advises governments on the effective use of regulation to achieve better social, environmental and economic outcomes; and

" calls for a "whole-of-government" approach to regulatory reform, with emphasis on the importance of consultation, co-ordination, communication and co-operation to address the challenges posed by the inter-connectedness of sectors and economies.

The OECD Regulatory Policy Committee, whose mandate is to assist Members and partner countries to build and strengthen capacity for regulatory quality and reform, has developed this piece of regulatory guidance, building on a robust assessment of over a decade of OECD experience in implementing systematic regulatory reform. The Recommendation was developed over a twelve-month period through extensive engagement with civil society, TUAC, BIAC, OECD Committees and the OECD Secretariat.

This new OECD Recommendation represents the insight, acknowledgement and political will of Member countries to promote better regulatory policies for better lives. I encourage Members to use the Recommendation actively, and implement it to support effective government, as well as promote the development of more prosperous, inclusive and green societies.

Angel Gurría

Secretary-General of the OECD 


\section{FOREWORD BY THE CHAIR OF THE OECD REGULATORY POLICY COMMITTEE}

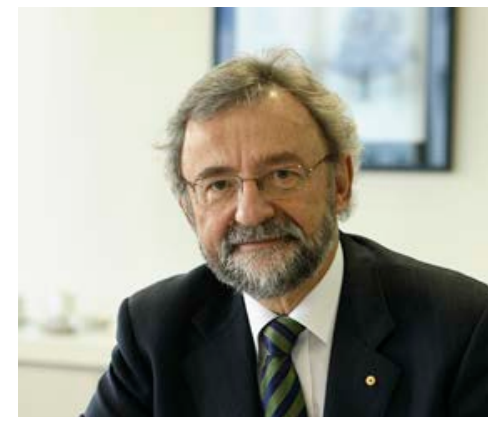

In the shadow of the global financial crisis, the importance of sound regulatory frameworks has become more evident than ever. Good regulation is essential if our economies are to function efficiently, while meeting important social and environmental goals. However achieving good regulation is a demanding task and one that is never over.

This new Recommendation of the Council on Regulatory Policy and Governance is the fruit of careful assessments of best practice identified by the Regulatory Policy Committee through a decade of reviews of OECD countries. It represents a maturing of thinking and learning from experience in this complex policy area. The Recommendation develops a systemic governance framework that can deliver ongoing improvements to the quality of regulations. It provides governments with advice on the development of institutions and the application of regulatory management tools. It also provides practical measures or benchmarks against which countries can assess their capacity to develop and implement quality regulation.

Participants at the international OECD Conference on "Regulatory Policy: Towards a New Policy Agenda" in October 2010, conscious of the increased importance of good regulation to meeting the challenges all countries now face, called for new principles to guide regulatory policy. The Recommendation of the Council on Regulatory Policy and Governance was developed by members of the Regulatory Policy Committee in the ensuing months. In addition to discussions within the committee there was broad public consultation on drafts of the Recommendation.

The Recommendation will provide the basis for a clearer dialogue with members and non-members about the policies, practices and institutions needed for systemic improvements to regulatory quality. It will facilitate the development of benchmarking practices, and provide a framework for advice to countries seeking to implement better regulatory governance where capacity is currently low.

As the incoming Chair of the Regulatory Policy Committee, it is a privilege to have the opportunity to support and commend this Recommendation.

Gary Banks AO

Chair, Regulatory Policy Committee, OECD

Dean of the Australia and New Zealand School

of Government 


\section{RECOMMENDATION OF THE COUNCIL ON REGULATORY POLICY AND GOVERNANCE}

\section{THE COUNCIL,}

HAVING REGARD to Articles 1, 2a), 3 and 5b) of the Convention on the Organisation for Economic Co-operation and Development of 14 December 1960;

HAVING REGARD to the Recommendation of the Council on Improving the Quality of Government Regulation [C(95)21/FINAL], including the OECD Reference Checklist for Regulatory DecisionMaking ;

HAVING REGARD to the 1997 OECD Report on Regulatory Reform [C/MIN(97)10 (summary) and C/ MIN(97)10/ADD], the 2005 Guiding Principles for Regulatory Quality and Performance [C(2005)52 and CORR1], the APEC-OECD Integrated Checklist for Regulatory Reform [SG/SGR(2005)4], and the Recommendation of the Council on Competition Assessment [C(2009)130];

NOTING the considerable progress made by Members and non-Members to improve the quality of regulation and of the tools and institutions for evidence-based decision making;

NOTING that the challenges facing governments today and in the foreseeable future include issues and problems with a regulatory dimension that have not been addressed systematically in previous OECD decisions, recommendations and principles;

RECOGNISING that democracy and the rule of law depend upon and reinforce sound regulatory frameworks;

RECOGNISING that regulations are one of the key levers by which governments act to promote economic prosperity, enhance welfare and pursue the public interest;

RECOGNISING that well-designed regulations can generate significant social and economic benefits which outweigh the costs of regulation, and contribute to social well-being;

NOTING that regulatory policy as a government policy framework for how regulations are made, assessed and revised should be carried out at the highest level by the office of the President or Prime Minister and calls for good governance practice to be implemented across departments and levels of government; 
RECOGNISING that the financial crises and economic cycles, innovation, social change, environmental challenges and the search for new sources of growth highlight the importance of regulatory frameworks for well-functioning markets and societies and of regulatory policies and institutions to cope with the inter-connectedness of sectors and economies;

RECOGNISING that the OECD has played a leading role in the international community to promote regulatory reform and the implementation of sound regulatory practices on a whole-of-government approach; and,

RECOGNISING that the Regulatory Policy Committee was created in 2009 to assist Members and non Members in building and strengthening capacity for regulatory quality and reform;

On the proposal of the Regulatory Policy Committee:

\section{RECOMMENDS that Members:}

1. Commit at the highest political level to an explicit whole-of-government policy for regulatory quality. The policy should have clear objectives and frameworks for implementation to ensure that, if regulation is used, the economic, social and environmental benefits justify the costs, the distributional effects are considered and the net benefits are maximised.

2. Adhere to principles of open government, including transparency and participation in the regulatory process to ensure that regulation serves the public interest and is informed by the legitimate needs of those interested in and affected by regulation. This includes providing meaningful opportunities (including online) for the public to contribute to the process of preparing draft regulatory proposals and to the quality of the supporting analysis. Governments should ensure that regulations are comprehensible and clear and that parties can easily understand their rights and obligations.

3. Establish mechanisms and institutions to actively provide oversight of regulatory policy procedures and goals, support and implement regulatory policy, and thereby foster regulatory quality.

4. Integrate Regulatory Impact Assessment (RIA) into the early stages of the policy process for the formulation of new regulatory proposals. Clearly identify policy goals, and evaluate if regulation is necessary and how it can be most effective and efficient in achieving those goals. Consider means other than regulation and identify the tradeoffs of the different approaches analysed to identify the best approach.

5. Conduct systematic programme reviews of the stock of significant regulation against clearly defined policy goals, including consideration of costs and benefits, to ensure that regulations remain up to date, cost justified, cost effective and consistent, and deliver the intended policy objectives.

6. Regularly publish reports on the performance of regulatory policy and reform programmes and the public authorities applying the regulations. Such reports should also include information on how regulatory tools such as Regulatory Impact Assessment (RIA), public consultation practices and reviews of existing regulations are functioning in practice. 
7. Develop a consistent policy covering the role and functions of regulatory agencies in order to provide greater confidence that regulatory decisions are made on an objective, impartial and consistent basis, without conflict of interest, bias or improper influence.

8. Ensure the effectiveness of systems for the review of the legality and procedural fairness of regulations and of decisions made by bodies empowered to issue regulatory sanctions. Ensure that citizens and businesses have access to these systems of review at reasonable cost and receive decisions in a timely manner.

9. As appropriate apply risk assessment, risk management, and risk communication strategies to the design and implementation of regulations to ensure that regulation is targeted and effective. Regulators should assess how regulations will be given effect and should design responsive implementation and enforcement strategies.

10. Where appropriate promote regulatory coherence through co-ordination mechanisms between the supranational, the national and sub-national levels of government. Identify cross-cutting regulatory issues at all levels of government, to promote coherence between regulatory approaches and avoid duplication or conflict of regulations.

11. Foster the development of regulatory management capacity and performance at sub-national levels of government.

12. In developing regulatory measures, give consideration to all relevant international standards and frameworks for co-operation in the same field and, where appropriate, their likely effects on parties outside the jurisdiction.

II. RECOMMENDS that Members take appropriate steps to implement high standards and to improve regulatory processes, and to use regulations wisely in pursuit of economic, social and environmental policies, and to take into account the principles expressed in this Recommendation, which are recalled and further developed in the Annex to this Recommendation of which it forms an integral part.

III. INVITES Members and the Secretary-General to disseminate this Recommendation;

IV. INVITES non-Members to take account of and adhere to this Recommendation;

V. INSTRUCTS the Regulatory Policy Committee to monitor the implementation of this Recommendation and to report thereon to the Council no later than three years following its adoption and regularly thereafter, in consultation with other relevant OECD Committees.

The Recommendation of the Council on Regulatory Policy and Governance [C(2012)37] was adopted on 22 March 2012. 


\section{ANNEX TO THE RECOMMENDATION OF THE COUNCIL ON REGULATORY POLICY AND GOVERNANCE}

1. Commit at the highest political level to an explicit whole-of-government policy for regulatory quality. The policy should have clear objectives and frameworks for implementation to ensure that, if regulation is used, the economic, social and environmental benefits justify the costs, distributional effects are considered and the net benefits are maximised.

1.1 Regulatory policy defines the process by which government, when identifying a policy objective, decides whether to use regulation as a policy instrument, and proceeds to draft and adopt a regulation through evidence-based decision-making. An explicit policy to ensure that regulations and regulatory frameworks serve the public interest should commit governments to:

» Adopt a continuous policy cycle for regulatory decision-making, from identifying policy objectives to regulatory design to evaluation;

» Use regulation when appropriate to achieve policy objectives, applying the Recommendation of the Council on Improving the Quality of Government Regulation [C(95)21/FINAL];

» Maintain a regulatory management system, including both ex ante impact assessment and ex post evaluation as key parts of evidence-based decision making;

» Articulate regulatory policy goals, strategies and benefits clearly;

» Systematically review the stock of regulations periodically to identify and eliminate or replace those which are obsolete, insufficient or inefficient;

» Develop, implement and evaluate a communications strategy to secure ongoing support for the goals of regulatory quality.

1.2 To achieve results, governments should:

» Adopt an integrated approach, which considers policies, institutions and tools as a whole, at all levels of government and across sectors, including the role of the legislature in ensuring the quality of laws; 
» Recognise that specific components such as impact assessment and administrative simplification are important but do not substitute for a comprehensive programme;

»Consider the impacts of regulation on competitiveness and economic growth;

» Commit to apply regulatory policy principles when preparing regulations that implement sectoral policies, and strive to ensure that regulations serve the public interest in promoting and benefitting from trade, competition and innovation while reducing system risk to the extent practicable;

» Monitor the impact of regulations and regulatory processes;

» Develop programmes to reduce the administrative and compliance costs of regulation without compromising legitimate regulatory objectives.

1.3 Governments should develop and maintain a strategic capacity to ensure that regulatory policy remains relevant and effective and can adjust and respond to emerging challenges. It is a core function of government to ensure that existing regulations are delivering the necessary level of public protection including having the strategic capacity to consider and identify if regulatory intervention is necessary and will be effective.

1.4 Governments should issue a formal and binding policy statement underpinning regulatory reform including guidelines for the use of regulatory policy tools and procedures. The design of institutional frameworks and resources necessary to implement regulatory policy including the enforcement of regulation should be assessed to ensure that they are adequate and address regulatory gaps.

1.5 Regulatory policy should include a preference for performance-based regulation, and should facilitate the efficient functioning of the market.

1.6 The regulatory policy should clearly identify the responsibilities of ministers for putting regulatory policy into effect within their respective portfolios. In addition, governments should consider assigning a specific Minister with political responsibility for maintaining and improving the operation of the whole-of-government policy on regulatory quality and to provide leadership and oversight of the regulatory governance process. The role of such Minister could include:

» Monitoring and reporting on the co-ordination of regulatory reform activities across portfolios;

» Reporting on the performance of the regulatory management system against the intended outcomes;

» Identifying opportunities for system-wide improvements to regulatory policy settings and regulatory management practices. 
2. Adhere to principles of open government, including transparency and participation in the regulatory process to ensure that regulation serves the public interest and is informed by the legitimate needs of those interested in and affected by regulation. This includes providing meaningful opportunities (including online) for the public to contribute to the process of preparing draft regulatory proposals and to the quality of the supporting analysis. Governments should ensure that regulations are comprehensible and clear and that parties can easily understand their rights and obligations.

2.1 Governments should establish a clear policy identifying how open and balanced public consultation on the development of rules will take place.

2.2 Governments should co-operate with stakeholders on reviewing existing and developing new regulations by:

" Actively engaging all relevant stakeholders during the regulation-making process and designing consultation processes to maximise the quality of the information received and its effectiveness.

» Consulting on all aspects of impact assessment analysis and using, for example, impact assessments as part of the consultation process;

» Making available to the public, as far as possible, all relevant material from regulatory dossiers including the supporting analyses, and the reasons for regulatory decisions as well as all relevant data;

» Structuring reviews of regulations around the needs of those affected by regulation, cooperating with them through the design and conduct of reviews including prioritisation, assessment of regulations and drafting simplification proposals;

» Evaluating the competitive effects of regulation on various economic players in the market.

2.3 Introduce regular performance assessments of regulations and regulatory systems, taking into account, among other things, the impacts on affected parties and how they are perceived. Communicate the results of these assessments to the public.

2.4 Make sure that policies and practices for inspections and enforcement respect the legitimate rights of those subject to the enforcement, are designed to maximise the net public benefits through compliance and enforcement and avoid unnecessary burdens on those subject to inspections.

2.5 All regulations should be easily accessible by the public. A complete and up-to-date legislative and regulatory database should be freely available to the public in a searchable format through a user-friendly interface over the Internet.

2.6 Governments should have a policy that requires regulatory texts to be drafted using plain language. They should also provide clear guidance on compliance with regulations, making sure that affected parties understand their rights and obligations. 
3. Establish mechanisms and institutions to actively provide oversight of regulatory policy procedures and goals, support and implement regulatory policy, and thereby foster regulatory quality.

3.1 A standing body charged with regulatory oversight should be established close to the centre of government, to ensure that regulation serves whole-of-government policy. The specific institutional solution must be adapted to each system of governance.

3.2 The authority of the regulatory oversight body should be set forth in mandate, such as statute or executive order. In the performance of its technical functions of assessing and advising on the quality of impact assessments, the oversight body should be independent from political influence.

3.3 The regulatory oversight body should be tasked with a variety of functions or tasks in order to promote high-quality evidence-based decision making. These tasks should include:

"Quality control through the review of the quality of impact assessments and returning proposed rules for which impact assessments are inadequate;

» Examining the potential for regulation to be more effective including promoting the consideration of regulatory measures in areas of policy where regulation is likely to be necessary;

» Contributing to the systematic improvement of the application of regulatory policy;

» Co-ordinating ex post evaluation for policy revision and for refinement of ex ante methods;

» Providing training and guidance on impact assessment and strategies for improving regulatory performance.

3.4 The performance of the oversight body, including its review of impact assessments should be periodically assessed. 
4. Integrate Regulatory Impact Assessment (RIA) into the early stages of the policy process for the formulation of new regulatory proposals. Clearly identify policy goals, and evaluate if regulation is necessary and how it can be most effective and efficient in achieving those goals. Consider means other than regulation and identify the tradeoffs of the different approaches analysed to identify the best approach.

4.1 Adopt ex ante impact assessment practices that are proportional to the significance of the regulation, and include benefit cost analyses that consider the welfare impacts of regulation taking into account economic, social and environmental impacts including the distributional effects over time, identifying who is likely to benefit and who is likely to bear costs.

4.2 Ex ante assessment policies should require the identification of a specific policy need, and the objective of the regulation such as the correction of a market failure, or the need to protect citizen's rights that justifies the use of regulation.

4.3 Ex ante assessment policies should include a consideration of alternative ways of addressing the public policy objectives, including regulatory and non regulatory alternatives to identify and select the most appropriate instrument, or mix of instruments to achieve policy goals. The no action option or baseline scenario should always be considered. $E x$ ante assessment should in most cases identify approaches likely to deliver the greatest net benefit to society, including complementary approaches such as through a combination of regulation, education and voluntary standards.

4.4 When regulatory proposals would have significant impacts, ex ante assessment of costs, benefits and risks should be quantitative whenever possible. Regulatory costs include direct costs (administrative, financial and capital costs) as well as indirect costs (opportunity costs) whether borne by businesses, citizens or government. Ex ante assessments should, where relevant, provide qualitative descriptions of those impacts that are difficult or impossible to quantify, such as equity, fairness, and distributional effects.

4.5 Regulatory Impact Analysis should as far as possible be made publicly available along with regulatory proposals. The analysis should be prepared in a suitable form and within adequate time to gain input from stakeholders and assist political decision making. Good practice would involve using the Regulatory Impact Analysis as part of the consultation process.

4.6. Ex ante assessment policies should indicate that regulation should seek to enhance, not deter, competition and consumer welfare, and that to the extent that regulations dictated by public interest benefits may affect the competitive process, authorities should explore ways to limit adverse effects and carefully evaluate them against the claimed benefits of the regulation. This includes exploring whether the objectives of the regulation cannot be achieved by other less restrictive means. 
4.7 When carrying out an assessment, officials should:

» Assess economic, social and environmental impacts (where possible in quantitative and monetised terms), taking into account possible long term and spatial effects;

» Evaluate if the adoption of common international instruments will efficiently address the identified policy issues and foster coherence at a global level with minimal disruption to national and international markets;

» Evaluate the impact on small to medium sized enterprises and demonstrate how administrative and compliance costs are minimised.

4.8 RIA should be supported with clear policies, training programmes, guidance and quality control mechanisms for data collection and use. It should be integrated early in the processes for the development of policy and supported within agencies and at the centre of government. 
5. Conduct systematic programme reviews of the stock of significant regulation against clearly defined policy goals, including consideration of costs and benefits, to ensure that regulations remain up to date, cost-justified, cost-effective and consistent and delivers the intended policy objectives.

5.1 The methods of Regulatory Impact Analysis should be integrated in programmes for the review and revision of existing regulations. These programmes should include an explicit objective to improve the efficiency and effectiveness of the regulations, including better design of regulatory instruments and to lessen regulatory costs for citizens and businesses as part of a policy to promote economic efficiency.

5.2 Reviews should preferably be scheduled to assess all significant regulation systematically over time, enhance consistency and coherence of the regulatory stock, and reduce unnecessary regulatory burdens and ensure that significant potential unintended consequences of regulation are identified. Priority should be given to identifying ineffective regulation and regulation with significant economic impacts on users and/or impact on risk management. The use of a permanent review mechanism should be considered for inclusion in rules, such as through review clauses in primary laws and sunsetting of subordinate legislation.

5.3 Systems for reviews should assess progress toward achieving coherence with economic, social and environmental policies.

5.4 Programmes of administrative simplification should include measurements of the aggregate burdens of regulation where feasible and consider the use of explicit targets as a means to lessen administrative burdens for citizens and businesses. Qualitative methods should complement the quantitative methods to better target efforts.

5.5 Employ the opportunities of information technology and one-stop shops for licences, permits, and other procedural requirements to make service delivery more streamlined and user-focused.

5.6 Review the means by which citizens and businesses are required to interact with government to satisfy regulatory requirements and reduce transaction costs. 
6. Regularly publish reports on the performance of regulatory policy and reform programmes and the public authorities applying the regulations. Such reports should also include information on how regulatory tools such as Regulatory Impact Assessment (RIA), public consultation practices and reviews of existing regulations are functioning in practice.

6.1 Review the effectiveness of programmes to improve the delivery of regulation inside government to ensure that they are effective and efficient and meet clearly identified objectives for public service delivery.

6.2 Design and assess data collection and information management strategies to ensure that the necessary high-quality information is available for the preparation of reports while avoiding the imposition of unnecessary administrative burdens.

6.3 Promote an external review function, including input by stakeholders and civil society. The assessment of RIA by the regulatory oversight body should be periodically evaluated by an independent third party, such as, for example, the National Audit Authority.

6.4 Simplification and reform programmes should be evaluated for the public value they deliver based on the resources required. Evaluation should focus primarily on the outcomes and effects for society ahead of the quantification of administrative burdens reduced. 
7. Develop a consistent policy covering the role and functions of regulatory agencies in order to provide greater confidence that regulatory decisions are made on an objective, impartial and consistent basis, without conflict of interest, bias or improper influence.

7.1 The legislation that grants regulatory authority to a specific body, should clearly state the objectives of the legislation and the powers of the authority.

7.2 To ensure that regulatory agencies are integrated in the regulatory system, governments should compile and maintain a public register of all entities in government with authority to exercise regulatory functions. The register should include the details of the statutory objectives of each regulatory authority and a listing of the regulatory instruments that it administers.

7.3 Independent regulatory agencies should be considered in situations where:

» There is a need for the regulatory agency to be independent in order to maintain public confidence;

» Both the government and private entities are regulated under the same framework and competitive neutrality is therefore required; and

» The decisions of regulatory agencies can have significant economic impacts on regulated parties and there is a need to protect the agency's impartiality.

7.4 Mechanisms of public accountability are required that clearly define how a regulatory agency is to discharge its responsibility with the necessary expertise as well as integrity, honesty and objectivity.

7.5 Regulatory agencies should be required to follow regulatory policy including engaging with stakeholders and undertaking RIA when developing draft laws or guidelines and other forms of soft law.

7.6 Agency performance should be subject to regular external evaluation. 
8. Ensure the effectiveness of systems for the review of the legality and procedural fairness of regulations, and of decisions made by bodies empowered to issue regulatory sanctions. Ensure that citizens and businesses have access to these systems of review at reasonable cost and receive decisions in a timely manner.

8.1 Citizens and businesses that are subject to the decisions of public authorities should have ready access to systems for challenging the exercise of that authority. This is particularly important in relation to regulatory sanctions, i.e. sanctions issued by an authority in virtue of a regulation.

8.2 This access should include the right to appeal the decisions of regulators on legal grounds, including on the grounds of procedural fairness and due process. This should also include the possibility to challenge in court the legality of any statutory provision, on which decisions of regulators are based, vis-à-vis higher hierarchical legal norms, including constitutional norms.

8.3 In principle, appeals should be heard by a separate authority than the body responsible for making the original regulatory decision.

8.4 Governments should, where appropriate, establish standard time periods within which applicants can expect an administrative decision to be made. 
9. As appropriate apply risk assessment, risk management, and risk communication strategies to the design and implementation of regulations to ensure that regulation is targeted and effective. Regulators should assess how regulations will be given effect and should design responsive implementation and enforcement strategies.

9.1 Governments should include their strategy on risk and regulation in their public statement underpinning regulatory reform. They should develop and regularly update guidance on the methodologies for risk assessment, management and communication concerning the use of regulation to achieve public and environmental protection.

9.2 Regulators should build an accountable system for review of risk assessments accompanying major regulatory proposals that present significant or novel scientific issues, for example through expert peer review.

9.3 Evaluate the likely effectiveness of risk strategies against their capacity to identify and inform regulatory actions that will help to avoid or mitigate catastrophic or systemic risks and minimise unintended consequences and "risk-risk" tradeoffs. Ensure that risk systems incorporate lessons from past events, including failures and close calls.

9.4 Governments should consider the use of risk-based approaches in the design and enforcement of regulatory compliance strategies to increase the likelihood of achieving compliance goals and to minimise the imposition of costs on citizens and businesses through compliance and enforcement procedures.

9.5 Regulators should be required to develop, implement and review regulatory compliance strategies against risk-based criteria.

9.6 Where the principle of precaution is applied, regulatory agencies must build an accountable system for review as scientific information becomes available. 
10. Where appropriate promote regulatory coherence through co-ordination mechanisms between the supra national, the national and sub-national levels of government. Identify cross cutting regulatory issues at all levels of government, to promote coherence between regulatory approaches and avoid duplication or conflict of regulations.

10.1 Design appropriate co-ordination mechanisms to develop regulatory policies and practices for all levels of government, including where appropriate through the use of measures to achieve harmonisation, or through the use of mutual recognition agreements;

10.2 Develop tools to diagnose regulatory issues that cut across levels of government (including supra-national organisations) to identify and reform overlapping regulations;

10.3 Capitalise on the proximity of sub-national governments to local firms and citizens to develop effective consultation procedures in the design of regulation and better reflect local needs in overall regulatory policy, at all levels of government;

10.4 Promote information sharing and transparency mechanisms between levels of government to overcome asymmetries of information and promote complementarities across regulations;

10.5 Disseminate innovative regulatory practices that take place at the local level, including making effective use of benchmarks among different jurisdictions;

10.6 Facilitate local variations and experimentation in regulatory approaches when it is nationally beneficial;

10.7 Supranational bodies with rule making powers should be encouraged to consider and apply all relevant aspects of this Recommendation. 
11. Foster the development of regulatory management capacity and performance at sub national levels of government.

11.1 Governments should support the implementation of regulatory policy and programmes at the sub-national level to reduce regulatory costs and barriers at the local or regional level which limit competition and impede investment, business growth and job creation.

11.2 Promote the implementation of programmes to assess and reduce the cost of the compliance with regulation at the sub-national level;

11.3 Promote procedures at the sub-national level to assess areas for which regulatory reform and simplification is most urgent to avoid legal vacuum, inconsistencies, duplication and overlap;

11.4 Promote efficient administration, regulatory charges should be set according to cost recovery principles, not to yield additional revenue;

11.5 Support capacity-building for regulatory management at sub-national level through the promotion of e government and administrative simplification when appropriate, and relevant human resources management policies;

11.6 Use appropriate incentives to foster the use by sub-national governments of Regulatory Impact Assessments to consider the impacts of new and amending regulations, including identifying and avoiding barriers to the seamless operation of new and emerging national markets;

11.7 Develop incentives to foster horizontal co-ordination across jurisdictions to eliminate barriers to the seamless operation of internal markets and limit the risk of race-to-the bottom practices, develop adequate mechanisms for resolving disputes across local jurisdictions;

11.8 Prevent conflict of interest through clear separation of the roles of sub-national governments as regulators and service providers. 
12. In developing regulatory measures, give consideration to all relevant international standards and frameworks for co-operation in the same field and, where appropriate, their likely effects on parties outside the jurisdiction.

12.1 In an increasingly globalised economy, international regulatory co-operation must become integral to systemic risk management and long-term policy planning.

12.2 Governments should take into account relevant international regulatory settings when formulating regulatory proposals to foster global coherence.

12.3 Governments should act in accordance with their international treaty obligations (for example under the ILO, UN and WTO/GATT Agreements which require that regulations accord foreign products and services treatment no less favorable than like products and services of national origin, or those originating in any other country).

12.4 Governments should co-operate with other countries to promote the development and diffusion of good practices and innovations in regulatory policy and governance.

12.5 Governments should contribute to international fora, including private or semi-private, which support greater International Regulatory Co-operation (IRC).

12.6 Governments should avoid the duplication of efforts in regulatory activity in cases where recognition of existing regulations and standards would achieve the same public interest objective at lower costs.

12.7 Processes of consultation on regulatory proposals should be open to receiving submissions from foreign and domestic interests. 


\section{APPENDIX 1 \\ BACKGROUND NOTE ON THE RECOMMENDATION OF THE COUNCIL ON REGULATORY POLICY AND GOVERNANCE}

This section provides background notes to the development of the principles in the Recommendation of the Council on Regulatory Policy and Governance. It is intended to assist the reader to understand the context of the elements in the Recommendation. It is presented for information only and does not form part of the Recommendation.

\section{Introduction}

The Recommendation of the Council on Regulatory Policy and Governance, expands on the existing OECD instruments on regulatory reform and management adopted since 1995, with a view to providing updated responses to the challenges of regulatory policy. The Recommendation covers regulatory policy, management and governance as a whole-of-government instrument that can and should be applied by sectoral ministries, regulatory and competition agencies.

The financial crisis has reinforced the need and highlighted the importance of a well-functioning regulatory framework for transparent and efficient markets with the right incentives. Societies need regulatory policies and institutions also to cope with the inter-connectedness of sectors and economies. Such fair, transparent and clear regulatory frameworks serve also as a sine qua non basic condition for dealing effectively with environmental and equality challenges in a society.

\section{Background}

OECD Ministers requested in 1995 that the OECD examine the significance, direction and means of reform in regulatory regimes in Member countries. The Recommendation of the Council on Improving the Quality of Government Regulation [C(95)21/FINAL] (1995 Recommendation) was the first-ever international statement of regulatory principles common to Members. Building on this fundamental text, and broadening it to embrace market openness, competition policy and microeconomic principles in a multidisciplinary framework, the OECD produced a Report on Regulatory Reform in 1997 [C/MIN(97)10 (summary) and C/MIN(97)10/ADD]. The report's recommendations have provided guidance to Members to improve regulatory policies and tools, strengthen market openness and competition, and reduce regulatory burdens. Moreover, these recommendations have provided the basis for OECD country reviews of Members carried out both in sectoral and policy areas.

The OECD Guiding Principles for Regulatory Quality and Performance [C(2005)52 and CORR1] (2005 Guiding Principles), based on the 1997 report's recommendations and evidence of the OECD country reviews carried out up to 2004 , reflect the state of regulatory policy evolution at the time. ${ }^{1}$ The Principles set out the importance of political commitment to regulatory reform, the

1 To date, 24 reviews of Members have been completed as well as 4 reviews of non-Members: Russia (2005), Brazil (2007), China (2008), Indonesia (2012). This body of research is available at www.oecd.org/regreform/backgroundreports. In addition, over the course of 2009 and 2010, the better regulation policies and practices of 15 Members of the European Union have been reviewed under the framework of the 2005 Guiding Principles. The "EU15" reports can be found at www.oecd.org/gov/regref/EU15. 
desirable characteristics of good regulation, and the links with competition and the elimination of barriers to trade and investment. The Principles, which emphasise effective and continuous regulatory management in order to secure high-quality regulation, were complemented in parallel by the APEC-OECD Integrated Checklist for Regulatory Reform [SG/SGR(2005)4].

Further to the 2005 Guiding Principles suggesting that regulations should be reviewed for their competition effects, the Competition Committee adopted in 2007 the Competition Assessment Toolkit, ${ }^{2}$ seeking to integrate and develop a best practice methodology for competition assessment. In early 2008, acknowledging that a number of countries had adopted some form of "competition assessment" and that methods for competition assessment had seen considerable progress since 2005, the Competition Committee developed a Recommendation on Competition Assessment which was adopted by the Council in 2009 [C(2009)130]. This Recommendation calls for evaluating policies to find those that may unduly restrict competition and for developing alternative policies that achieve the same objectives with lesser harm to competition.

Related work has been carried out by the Committee on Consumer Policy, which developed a Consumer Policy Toolkit in 2010 (OECD, 2010d). The toolkit establishes a framework for identifying and evaluating consumer problems and provides methods for determining how education, information and other non regulatory and regulatory approaches can best be used to address those problems, without undermining competition.

While the 1995 Recommendation and the 2005 Principles remain relevant, it was acknowledged at the International OECD Regulatory Policy Conference of 28-29 October 2010 that their coverage should be expanded in the light of more recent experience, additional reviews, and the broad mandate of the Regulatory Policy Committee. Likewise, the report Regulatory Policy and Governance: Supporting Economic Growth and Serving the Public Interest, OECD (2011), which synthesises 10 years of OECD work on regulatory reform, calls for a revision and update of collective thinking on regulatory policy and governance.

For the OECD, regulation is defined broadly, referring to the diverse set of instruments by which governments set requirements on enterprises and citizens. Regulations include laws, formal and informal orders and subordinate rules issued by all levels of government, and rules issued by non-governmental or self-regulatory bodies to which governments have delegated regulatory powers $(O E C D, 1997)$. Effective regulatory governance maximises the influence of regulatory policy to deliver regulations which will have a positive impact on the economy and society, and will meet underlying public policy objectives. It is concerned with the design and implementation of regulation as well as ensuring compliance. It implies an integrated approach to the deployment of regulatory policies, tools and institutions.

The Recommendation presents Regulatory Policy and Governance as a whole-of-government activity integrated in the policy cycle of regulatory design, enforcement, review and evaluation supported by appropriate institutions. It emphasises the importance of co-ordination, consultation, communication and co-operation throughout the policy cycle. It focuses to a greater extent on the need for risk assessment and regulatory co-ordination across levels of government, and the organisation of regulatory agencies than have previous OECD instruments. Together the principles expressed in the Recommendation provide countries with the basis for a comprehensive assessment of the performance of the policies, tools and institutions that underpin the use of efficient and effective regulation to achieve social, environmental and economic goals.

2 See DAF/COMP(2007)5, DAF/COMP(2007)6, DAF/COMP(2007)7 and DAF/COMP(2007)8 and OECD (2011), Competition Assessment Toolkit: Principles, OECD, Paris, for the most recent versions, also to be found at www.oecd.org/competition/ toolkit. 
The Recommendation has been developed by the Regulatory Policy Committee through a thorough process of public and committee engagement during 2011. An early consultation version of the draft Recommendation was deliberated upon by the Regulatory Policy Committee in April 2011. A consultation version reflecting the views of the Committee was subsequently published and comments were sought from the public in June and July of 2011. Following this, an amended version was distributed for discussion by, and input from, other OECD Committees and the OECD Secretariat.

The draft Recommendation was broadly welcomed and a range of helpful comments were received from within the OECD and from external sources, in particular from academic commentators, BIAC and TUAC, and from the Competition Committee and the Public Governance Committee. To aid transparency, where the approval of submitters was provided, public submissions were posted on the regulatory policy section of the OECD website. The advice obtained through this process of consultation significantly improved and developed the draft of the Recommendation which was discussed again at the November 2011 meeting of the Regulatory Policy Committee. Following final refinements and revisions to the detail of the Recommendation in close discussion with Committee delegates, the text of the draft Recommendation was approved by the Regulatory Policy Committee on 16 January 2012 for submission to Council.

\section{Discussion of the Principles in the Recommendation}

\section{Explicit Policy on Regulatory Quality}

Regulation is one of the three key levers of formal state power (together with taxing and spending). Of critical importance in shaping the welfare of economies and society, it may also be considered as the ultimate horizontal policy; when carried out effectively, regulatory policy complements the formulation and implementation of all other policies. The objective of regulatory policy is to ensure that the regulatory lever works effectively, so that regulations and regulatory frameworks are in the public interest.

Regulatory reviews have consistently highlighted the importance of adopting a "whole-of-government" policy, able to take into account in a dynamic perspective the interplay between the different institutions involved in the regulatory process and to overcome the obstacles created by a traditional compartmentalisation of functions. The adoption of a"whole-of-government" policy implies the capacity to devise the mechanisms of co-operation needed to achieve defined policy objectives.

If a "whole-of-government" perspective is essential in order to capture the interrelations which allow a proper functioning of central government and determine the quality of regulation, the promotion of regulatory quality culture can help spread a sense of increased responsibility for reform results. In many countries, administrations have not yet fully integrated the need for regulatory quality into their policy processes.

Ensuring the quality of the regulatory structure is a dynamic and permanent role of governments and Parliaments. Governments must be actively engaged in assuring the quality of regulation, not reactively responding to failures in regulatory quality. In advanced countries this concept, which implies the need to link the evaluation of existing regulations as they operate to the design of new regulations, is evolving into regulatory governance. Regulatory governance is grounded in the principles of democratic governance and engages a wider domain of players including the legislature, the judiciary, sub-national and supranational levels of government and international standard setting activities, including those of the private sector. Regulatory policies, tools and institutions make up the elements of the analytical framework that the OECD has advocated for a successful approach to regulatory governance. 
Political commitment to regulatory reform has been unanimously highlighted by country reviews as one of the main factors supporting an explicit policy on regulatory quality. An effective regulatory policy should be adopted at the highest political level, and the importance of regulatory quality should be adequately communicated to lower levels of the administration. Political commitment can be demonstrated in different ways. The creation of a central oversight body in charge of promoting regulatory quality is a key element to show the political commitment of government to spread awareness among the different actors involved in the regulatory process. That said, the call for strong leadership should not be read as endorsing a top-down approach to reform or a preference for unilateral action by the executive. Successful leadership is often about winning consent rather than securing compliance.

A key component for a successful system of regulatory quality management is the adoption of a clear political commitment to the established principles for regulatory reform. Governments need to ensure that there is effective leadership and oversight of the regulatory governance process. In addition, the assignment of specific responsibilities for all aspects of regulatory management and reform and the creation of a clear framework of accountability are essential for the success of a regulatory reform programme.

The appointment of responsibility for regulatory policy at the ministerial level helps to ensure the political commitment to the goals of the regulatory policy. However, the range of programme responsibilities within a system of regulatory management is complexand shared across government. These include portfolio and sector specific responsibilities for ensuring that regulatory quality measures are applied, such as for example, the application of Regulatory Impact Assessment (RIA), or simplification measures to the development of regulations in particular policy areas. Beyond the portfolio responsibilities, however, there is also a need to allocate the system wide responsibilities for monitoring and promoting the success of the government wide policy on regulatory reform.

A clear framework of accountability would identify the responsibilities of ministers to ensure that the requirements of the regulatory management system are implemented within their portfolio areas, as well as the allocation of system-wide responsibilities for regulatory policy and governance. System-wide responsibilities should be assigned to a specific ministerial role in cabinet to provide leadership and oversight of the regulatory governance process, and monitor and report on the coordination of regulatory reform activities across portfolios. The responsibility includes preparing a report on the performance of the regulatory management system, and identifying opportunities for system-wide improvements to regulatory policy settings and regulatory management practices.

In some aspects of regulatory management this systemic role may necessarily be shared with the functions of other ministers whose roles complement the efficient functioning of regulatory management systems. This may include, for example the role of the Minister of Justice in ensuring the legal quality of regulations and maintaining the legislative database, or the role of the Treasurer in promoting government-wide economic policy. There is nevertheless merit in assigning a specific role for Regulatory Policy to a lead Minister.

This practice is in fact already broadly adopted across OECD. In 2008, 24 jurisdictions reported that their governments had assigned responsibility for promoting government-wide progress on regulatory reform to a specific Minister. 


\section{Communication, Consultation and Engagement}

Regulatory Policy should consider the beneficiaries from regulatory protection as well as those that incur regulatory obligations. Persons concerned with and affected by regulation include citizens, businesses, consumers, and employees (including their representative organisations and associations), the public sector, non-governmental organisations, international trading partners and other stakeholders. It is not always possible to define public interest as the sum of interests of individual stakeholders; however adopting a public-oriented perspective on regulatory policy should be a goal of government to assess the design and implementation of regulation and identify opportunities for improvement. Open government enables public scrutiny, gathering facts from those affected by proposals, safeguards against corruption, and promotes citizens' trust in government, through increased transparency and public participation. It facilitates the goal of nondiscrimination, by supporting equal access and treatment for all citizens under the law.

The public should enjoy unimpeded access to regulation, free of charge. This increases regulatory transparency and reduces possibilities for abuse of discretion and for corrupt behaviour from public officials.

A process of communication, consultation and engagement which allows for public participation of stakeholders in the regulation-making process as well as in the revision of regulations can help governments understand citizens' and other stakeholders' needs and improve trust in government. Also, it can help governments collect more information and resources, increase compliance, and reduce uninformed opposition. It may enhance transparency and accountability as interested parties gain access to detailed information on potential effects of regulation on them.

A wide spectrum of consultation tools should be used to engage a broad diversity of stakeholders within the population. Modes of consultation need to reflect the fact that different legitimate interests do not have the same access to the resources and opportunities to express their views to government, and that a diversity of channels for the communication of these views should be created and maintained. Sufficient time must be provided to allow stakeholders the opportunity to consider proposed regulations and to participate in the regulation making process.

Collecting information on the impact of regulation on the public, including their perception of regulation helps governments to structure their policies to address perceived issues and better prioritise reforms to focus on those areas that may warrant regulation, or where regulation may be unnecessarily burdensome.

The reduction of unnecessary regulatory burdens and the development of sound regulation helps to support economic growth innovation and competition and also builds public trust in the administration as an effective rule maker. In designing regulation governments need to be aware of the incidence of regulatory costs on businesses and citizens and of disproportionate impacts on small to medium-sized enterprises and micro businesses. 


\section{Regulatory Oversight}

Political accountability is important, because regulatory oversight bodies need to be able to exert some influence on regulators who may have their own political constituencies. Just as regulatory agencies need oversight, regulatory oversight bodies also warrant oversight, for instance by the head of state, by a minister, by the legislature or by the public.

The type of authority accorded to the regulatory oversight body may depend importantly on the source of its mandate. For example, authority conferred by a statute enacted by the legislature may have broader application to reviews of future legislation, whereas authority conferred by order of the President or Prime Minister may be more confined to oversight of secondary regulation within the executive branch.

The exact location of a regulatory oversight body within the structure of government may depend on a number of considerations. Oversight bodies have been placed at the centre of government supervised by the head of state. There may be the need to locate a regulatory oversight body in a finance or economics-oriented ministry, especially if the centre of government lacks the institutional capacity and resources to carry out regulatory oversight. In addition, mixed institutional arrangements for oversight bodies are also possible, combining the different responsibilities of oversight and creating a network of bodies operating at different levels of government. External oversight can also play a complementary role, for example, through the use of advisory groups representing business interests to monitor and report on the progress of government reform initiatives.

Regulatory oversight should be based on expertise, in the form of a trained professional staff capable of undertaking evaluation of regulatory proposals and options, as well as their impacts on business and society. Technical knowledge can reveal and make transparent the significant impacts, tradeoffs, and alternatives of regulatory choices - informing politicians and policy makers as well as the public of both the promise and pitfalls of regulation.

\section{Integrated Regulatory Impact Assessment}

Regulatory Impact Assessment (RIA) ${ }^{1}$ is both a tool and a decision process for informing political decisions makers on whether and how to regulate to achieve public policy goals. Improving the evidence base for regulation through an ex ante (prospective) impact assessment of new regulations is one of the most important regulatory tools available to governments. The aim is to improve the design of regulations by assisting policy makers to identify and consider the most efficient and effective regulatory approaches, including the non regulatory alternatives before they make a decision. One method of doing so is by analysing the evidence for the costs and benefits of regulation and of alternative means of achieving policy goals and to identify the approach that is likely to deliver the greatest net benefit to society.

1. RIA is also referred to as Impact Analysis (IA), usually in circumstances where it is applied to policy development more broadly and not confined by administrative procedure to only those policy decisions which involve a consideration of whether or not to use regulation. This is the case, for example, in the European Commission. Regulatory Impact Assessment (RIA) is also routinely referred to as Regulatory Impact Analysis, sometimes interchangeably. A Regulatory Impact Statement (RIS) documents the Regulatory Impact Assessment. 
A well-designed RIA can assist in promoting policy coherence by making transparent the tradeoffs inherent in regulatory proposals, identifying who is likely to benefit from the distributional effects of regulation and who will bear the costs, and how risk reduction in one area may create risks for other areas of government policy. A comprehensive RIA incorporates an assessment of the economic, social and environmental impacts. RIA can improve the use of evidence in policy making, can identify an appropriate response to an identified problem and can reduce the incidence of regulatory failure arising from regulating when there is no case for doing so, or failing to regulate when there is a clear need.

However, the effective use of impact assessment is demanding in terms of resources and expertise and is often hampered through poor application or political and bureaucratic resistance. RIA is sometimes misconceived as a substitute for policy making, when in fact it is intended to facilitate and strengthen the policy process, by helping to assess whether regulations are needed and if they will be effective. With the proper focus an RIA can be integrated with policy development rather than serve as a procedural hurdle. OECD experience demonstrates that the support of a well-resourced regulatory oversight function helps to integrate impact assessment in the policy and rule-making process, and to raise the quality of assessments. These bodies should provide support and training in the analysis of regulation and review the quality of impact assessments.

Impact assessment processes should be closely linked with general consultation processes for the development of new regulations through for example, roadmaps, giving early notice of possible regulatory initiatives and related consultation and impact assessment work and the use of a consultation stage Regulatory Impact Assessment. The results of the consultations, together with individual contributions, should as far as possible, be made publicly available (including online where appropriate) in order to ensure a high level of transparency and reduce the risks of regulatory capture.

The consideration of a range of alternative approaches to traditional "command and control" regulation, including complementary measures such as co-regulation, helps to ensure that the most efficient and effective approaches are used for meeting policy goals. Experience shows that governments must lead strongly to overcome inbuilt inertia, risk aversion and a "regulate first, ask questions later" culture. At the same time care must be taken when deciding to use light-handed approaches such as self-regulation, to ensure that public policy objectives are attained.

\section{Reviews of the Regulatory Stock-expost Regulatory Evaluation}

The evaluation of existing policies through ex post impact analysis is necessary to ensure that regulations are effective and efficient. In some circumstances, the formal processes of expost impact analysis may be more effective than ex ante analysis at informing ongoing policy debate. This is likely to be the case for example, if regulations have been developed under pressure to implement a rapid response. Consideration should be given early in the policy cycle to the performance criteria for ex post evaluation, including whether the objectives of the regulation are clear, what data will be used to measure performance as well as the allocation of institutional resources. It can be difficult to direct scarce policy resources to review existing regulation; accordingly, it is necessary to systematically programme the review of regulation to ensure that expost evaluation is undertaken. Practical methods include embedding the use of sunset clauses or requirements for mandatory periodic evaluation in rules, scheduled review programmes and standing mechanisms by which the public can make recommendations to modify existing regulation. 
Careful consideration should be given to the design and organisation of the review procedures to deliver meaningful results from reviews. For significant regulations, the conduct of reviews should be independent of the agencies administering the regulation. As regulations usually work in concert with other regulations and administrative procedures, it is important that the processes for review look at the effectiveness of regulation in achieving their policy goals and do not simply take an incremental and atomistic approach. Complementary approaches may, for example focus on the review of industry sectors or opportunities for promoting innovation.

In the absence of a process of renewal, the volume of red tape tends to accrete over time. This complicates the daily life of citizens and impedes the efficient functioning of business. Red tape can be particularly burdensome on small to medium-sized enterprises, where the proportion of resources diverted to administrative functions is greater than for large firms. Red tape can also be burdensome for the public sector and reduce efficiency. Reducing the administrative burden of government regulations on citizens, businesses and the public sector should be a part of the government's strategy to improve economic performance and productivity. Nevertheless, reducing other regulatory burdens is equally important as administrative costs represent only a relatively small percentage of the overall costs governments impose on entities subject to regulation.

Rapid developments in information and communications technology are creating new avenues for streamlining the ways in which governments interact with citizens and businesses, and to make governments more efficient. It is necessary for governments to regularly and systematically consider how to employ the opportunities afforded by new technologies to harness network effects to reduce the transaction costs of dealing with governments and improve the experience from the perspective of users of government services.

\section{Reviewing Performance of Regulatory Reform Programmes and Regulatory Policy}

Information on the performance of regulatory reform programmes is necessary to identify and evaluate if regulatory policy is being implemented effectively and if reforms are having the desired impact. Regulatory performance measures can also provide a benchmark for improving compliance by agencies with the requirements of regulatory policy, such as, for example, reporting on the effective use of impact assessment, consultation, simplification measures and other practices.

Transparency is an important feature for ensuring the effectiveness of the information. This depends on the public release of reviews and of performance data to allow external stakeholders to consider and comment on performance information, and to provide incentives to agencies to improve their practices.

Regulation inside government refers to the regulations imposed by the state on its own administrators and public service providers (for example government agencies or local government service providers). In an environment of scarce resources, it is necessary to improve the efficiency and effectiveness of the regulations and the practices that apply within the administration and by public service providers. The reduction of administrative burdens inside government can improve the quality and efficiency of internal regulation in order to reduce costs and release resources for improved public service delivery. 


\section{The Organisation of Regulatory Agencies}

Legislation that grants regulatory authority to a specific body should explicitly specify the objectives for doing so. In particular, the legislation should spell out the policy objective it aims to achieve rather than the process by which the objectives will be achieved. The appropriate degree of prescription or detail in legislation is a matter for judgement. Principle based legislation is likely to be the most appropriate way of meeting policy objectives in complex or rapidly changing policy environments. However, this is contingent on the regulatory authority having the necessary sectoral expertise and capacity to implement its legislative responsibilities. In addition it should be acknowledged that it imposes communication challenges that must be managed by the regulatory agency.

It is important to consider how governance arrangements of a regulatory agency will influence public trust. Creating a regulatory agency independent from the government and from those it regulates can provide greater confidence that decisions are fair and impartial. This may be warranted when the decisions of the regulatory agency have significant financial and market consequences and are required to be arm's length from the political process to reduce the regulatory risk of investments. Accordingly, when a separate regulatory function is established, consideration should be given as to whether the regulatory agency is set up outside ministerial structures (while still being accountable to the government) or is set up as an administrative unit within a ministry. Arrangements should also focus on avoiding a situation of regulatory capture of the agency.

A regulatory agency exists to achieve objectives deemed by the government to be in the public interest. It operates within/ in accordance of the powers conferred by the legislature. Therefore, a system of accountability needs to take account of the performance of regulatory duties. Regulatory agencies should report regularly - either to the legislature or the responsible ministry in their policy area - on the fulfilment of their objectives and the discharge of their functions, including through meaningful performance indicators. Key operational policies and other guidance material, covering matters such as compliance, enforcement and decision review should be publicly available. Regulatory agencies should establish processes for and publish arm's length internal review of significant decisions. Likewise, regulatory agencies should be subject to independent review of regulatory decisions especially those that have significant economic impacts on regulated parties.

Effective co-ordination of regulatory activities can also bring significant administrative benefits. The activities of one regulatory agency can overlap and impact on another; either because the harms they regulate are of a similar nature (for example related to consumer protection), or because they interact with the same businesses. Regulators should be encouraged to see themselves as part of an integrated system of regulation and to work together and learn from each other. The first step is to improve awareness of the complexity in the regulatory system by developing a complete list of regulatory agencies, including their functions and responsibilities. 


\section{Administrative and Judicial Review}

Regulatory authorities must exercise their authority only within the scope permitted by their legal powers, treat like cases in a like manner and have justifiable reasons for decisions, and for any departure from regular practice. Embedding the principles in law and providing for effective appeals processes prevents abuse of discretionary authority, and preserves the integrity of the regulatory system.

It is important to ensure that access to appeal procedures is swift and un complicated without the excessive burden of legal costs. On the other hand it is also necessary to prevent creating the incentives for forum shopping or for frivolous and vexatious appeals by those affected by regulatory decisions, which unnecessarily ties up the resources of regulators and reduces regulatory certainty.

To promote economic activity and support business confidence there should be fast resolution of all approval processes necessary to start a business, and infringement processes should be concluded within clear timeframes. The establishment of fixed time limits within which an authority should be expected to give notice of a decision, combined with silence means consent rules, are mechanisms to improve the responsiveness of regulatory agencies and to facilitate quick resolution of issues in standard cases. It is acknowledged that exceptions from standard time frames are likely to be necessary to allow for special and complex matters. However, good practice is facilitated by identifying a narrow list of areas where exceptions may be applied and, even in such cases, applicants should expect to receive notice of the progress of their administrative matter.

\section{Risk and Regulation}

Regulation is often developed as a measure to respond to a perceived risk. In such cases, the design of regulatory solutions should be based on an assessment of the risk that they are designed to address. Governments should have developed systems for applying scientific principles to the estimation of risks. Whenever relevant, policy proposals should be examined for their potential riskrisk tradeoffs, where a reduction in risk in one area inadvertently gives rise to an increased risk in another area.

Risk assessment, risk management and risk communication are part of a cycle of responsive regulation. Risk assessment is a key analytical tool to identify and assess the extent of a potential hazard and to estimate the probability and consequences of negative outcomes for humans, property or the environment. Risk management refers to the design and implementation of actions and remedies to address risks through a consideration of potential treatments and the selection of the most appropriate course, or combination of courses, of action. Risk communication refers to the methods and practices for educating and informing the public about risks when making risk tradeoffs, and is a critical component of the risk policy cycle. Improving public understanding of the nature of the risks and the risk management measures can increase the public acceptance of the risk elements that cannot be reduced through further management.

Furthermore, as demonstrated by the international financial crisis, the risk assessment and management systems of regulators have to be explicitly designed to take into account the consequences of systemic risk and of rare catastrophic events. This is complex but will involve having systems to incorporate the lessons of past crisis and of narrowly averted events. Regulatory agencies should therefore assess their compliance and enforcement strategies to identify and allocate resources to the most critical risks. 


\section{Regulatory Coherence across Levels of Government}

The distinction between federal and unitary countries does not encompass the range and variety of the institutional context within which all countries are decentralised to one degree or another. What is consistent is that the relationship among levels of government resulting from decentralisation is characterised by mutual dependence, since it is impossible to have a complete separation of policy responsibilities and outcomes among levels of government. It is necessarily a complex relationship, simultaneously vertical, across different levels of government, horizontal, within the same level of government, and networked.

The exercise of regulatory authority by multiple levels of government should, in principle, operate in concert to achieve national economic and social policy goals, such as the creation of common markets and the equal protection of citizens and of the environment. However, the complexity of these relationships creates the potential for horizontal and vertical gaps in the capacities of government to operate effectively and in harmony. These gaps include: the fiscal capacity of governments to meet obligations, information asymmetries between levels of government, gaps in administrative accountability, with administrative borders not corresponding to functional economic and social areas at the sub-national level, gaps in policy design, when line ministries take purely vertical approaches to cross-sectoral regulation that can require co-design or implementation at the local level and often a lack of human, or infrastructure resources to deliver services.

Members and non-Members are increasingly developing and using a wide variety of mechanisms to help bridge these gaps and improve the coherence of regulatory multi-level policy making. These mechanisms may be "binding", such as legal mechanisms, or "soft", such as platforms of discussion, and they must be sufficiently flexible to allow for territorially specific policies. Involvement of subnational governments in regulation-making takes time, but medium-long term benefits should outweigh the costs of co-ordination. Countries that successfully approach regulatory reform in this way can expect to reap productivity benefits across the economy, through the redesign of regulatory process and the removal of regulatory burdens and better co-ordinated action.

\section{Regulatory Management Capacity at Sub-national Level}

Co-ordination across levels of government should be accompanied by efforts to develop regulatory management capacity at sub-national level. National governments have a role to play in supporting the development of local capacities for regulatory management, through appropriate governance and fiscal arrangements and incentives, as well as providing advice and training to officials.

Gaps in capacity not only involve the ability of sub-national governments to implement national regulation but also to define their own strategy for regulatory management, including the assessment of regulatory impact and reforms needed. As demands for regulatory governance become more strategic, the capacity of the sub-national level is often insufficient or reveals important disparities among local actors (in particular across urban and rural areas). There is also a trade-off between the salience of information available at the local level (through close contact with citizens and businesses) and the risk of capture, or a narrow conception of the public interest.

Limited capacities impact both the implementation of regulation and its design across levels of government. Inter-dependencies across levels of government permeate public policy with both domestic and global implications. Most of the investment for green growth and in infrastructure takes place at the local/regional levels. In energy policy, cities emit about $76 \%$ of the world's energyrelated greenhouse gases. To be effective, the commitments assumed by central governments need to be properly implemented at the local level. 


\section{International Regulatory Co-operation}

In an increasingly globalised economy, international regulatory co-operation must become integral to risk management and long-term policy planning including enhancing transparency for citizens and businesses.

Formalised governance arrangements for international regulatory co-operation, and their practical consequences, are not well understood. The crisis of 2008 exposed regulatory gaps in the financial sector; issues of co-ordination across regulations in the energy, health, environment, transport and consumer safety fields are also evident. Globalisation has been and will remain a key agent of change, raising issues of competitiveness in any assessment of a country's domestic regulatory agenda. The domestic regulatory policy agenda must take account of the problems of cross-border risks, and contribute to preventing the development of international systemic problems which will have consequences within a country's borders. Governments have to balance the goals of preventing regulation from becoming an inappropriate impediment to trade in goods and services, while also ensuring that regulatory systems are effective at achieving public policy goals and promoting confidence in the capacity of the regulatory system.

The challenges are pre-eminently a governance issue, involving both foreign and domestic stakeholders and authorities. Potentially regulatory co-operation can be practised at an agency level or on a government-wide basis; it can involve a commitment to exchange information about current regulations and new regulatory initiatives, or to consult with counterpart agencies in other jurisdictions before taking action; or it can be based on the collaborative identification of regulatory problems to be addressed and the joint identification of a regulatory agenda. In the latter case, cooperation in the performance of various technical and policy analysis is needed to arrive at solutions to the problems selected for action, and the joint development of regulatory texts.

At a minimum, governments should ensure that systems for rule making take into account the potential impacts on parties outside of the national boundaries and provide opportunities for consultation with external partners on the development of regulations. The development of rules in international forums should be informed by good impact assessment practices, and be no more restrictive than is necessary to achieve legitimate regulatory goals.

Governments should consider basing their regulatory approaches on relevant international standards and more generally take into account their international obligations, for example under the WTO/GATT Agreements. In particular, governments must ensure that their regulations accord foreign products and services treatment no less favourable than like products and services of national origin or those originating in any other country. 


\section{BIBLIOGRAPHY}

OECD (1995), Recommendation of the Council of the OECD on Improving the Quality of Government Regulation, including the OECD Reference Checklist for Regulatory Decision Making, 9 March 1995, OECD/GD(95)95, OECD, Paris.

OECD (1997), The OECD Report on Regulatory Reform, OECD, Paris.

OECD (2005), APEC-OECD Integrated Checklist for Regulatory Reform, OECD, Paris.

OECD (2005), Guiding Principles for Regulatory Quality and Performance, OECD, Paris.

OECD (2009a), OECD Reviews of Regulatory Reform, Regulatory Impact Analysis: A Tool for Policy Coherence, OECD Publishing, Paris.

OECD (2009b), "Bridging the Gaps between levels of government", Policy Brief, OECD, Paris.

OECD (2009c), Recommendation of the Council on Competition Assessment, C(2009)130, OECD, Paris, 22 October.

OECD (2009d), Indicators of Regulatory Management Systems, 2009 Report, OECD, Paris, December.

OECD (2010a), Better Regulation in Europe, Reviews in 15 countries available online at www.oecd.org/gov/regref/eu15.

OECD (2010b), OECD Reviews of Regulatory Reform, Risk and Regulatory Policy: Improving the Governance of Risk, OECD Publishing, Paris.

OECD (2010c), OECD Reviews of Regulatory Reform, Australia, Towards a Seamless National Economy, OECD Publishing, Paris.

OECD (2010d), Consumer Policy Toolkit, OECD Publishing, Paris.

OECD (2011b), Making the Most of Public Investment in a Tight Fiscal Environment Multi-Level Governance Lessons from the Crisis, OECD Publishing, OECD, Paris.

OECD (2011c), Competition Assessment Toolkit: Principles, OECD, Paris, available at www.oecd.org/competition/toolkit.

OECD (2011d), Competition Assessment Toolkit: Guidance, OECD, Paris, available at www.oecd.org/competition/toolkit.

OECD (2011e), Regulatory Policy and Governance: Supporting Economic Growth and Serving the Public Interest, OECD Publishing, Paris. 


\section{ORGANISATION FOR ECONOMIC CO-OPERATION AND DEVELOPMENT}

The OECD is a unique forum where governments work together to address the economic, social and environmental challenges of globalisation. The OECD is also at the forefront of efforts to understand and to help governments respond to new developments and concerns, such as corporate governance, the information economy and the challenges of an ageing population. The Organisation provides a setting where governments can compare policy experiences, seek answers to common problems, identify good practice and work to co-ordinate domestic and international policies.

The OECD member countries are: Australia, Austria, Belgium, Canada, Chile, the Czech Republic, Denmark, Estonia, Finland, France, Germany, Greece, Hungary, Iceland, Ireland, Israel, Italy, Japan, Korea, Luxembourg, Mexico, the Netherlands, New Zealand, Norway, Poland, Portugal, the Slovak Republic, Slovenia, Spain, Sweden, Switzerland, Turkey, the United Kingdom and the United States. The European Commission takes part in the work of the OECD.

OECD Publishing disseminates widely the results of the Organisation's statistics gathering and research on economic, social and environmental issues, as well as the conventions, guidelines and standards agreed by its members. 
Slovenia

\section{Czech Republic}

\section{United States}

\section{Australia}

Belgium

\section{Iceland}

\section{Mexico}

\section{Austria}

Chile

Korea

\section{Greece}

United Kingdom

New Zealand

Hungary 